\title{
Leadership Style and Employee Performance: The Case of Oil and Gas Industry
}

American Journal of Social Sciences and Humanities

Vol. 5, No. 2, 286-301, 2020 e-ISSN: $2520-5382$

(D) Check for updates $\begin{gathered}\text { check for } \\ \text { updates }\end{gathered}$

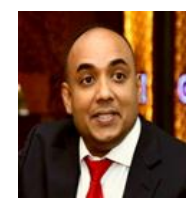

iD Basil John Thomas Email:drbasilit@gmail.com

Assistant Professor, Department of Business, Sur University College, Sultanate of Oman.

\begin{abstract}
Here an attempt is made to investigate the leadership style eventually practiced in the organisations and its impact on the perpetual development of the employee performance particularly considering the Oil and Gas Industry of Oman. The study eventually has found that it is the responsibility of the leaders who can motivate the workforce to move in a right direction to achieve the destined goals. The study has also found that in the current scenario where the Western world is trying to establish their entity in the oil and gas business, if an organisation is not guided properly by a leader, chances of crumbling down before the intense pressure is quite common. The study has also essentially found that autocratic leadership style is quite effective in the short term while the democratic leadership style is useful for all time. The study recommends that a leader should be proactive in nature and must be capable of understand the internal and external scenario that the organisation is currently facing or would have to face in the coming days. It would help the leader guide the workforce through the proper channel and attain the predestined objectives set beforehand.
\end{abstract}

Keywords: Performance, Employees, Leadership, Development, Oil and gas industry, Organizations.

DOI: $10.20448 / 801.52 .286 .301$

Citation | Basil John Thomas (2020). Leadership Style and Employee Performance: The Case of Oil and Gas Industry. American Journal of Social Sciences and Humanities, 5(1): 286-301.

Copyright: This work is licensed under a Creative Commons Attribution 3.0 License

Funding: This study received no specific financial support.

Competing Interests: The authors declare that they have no competing interests.

History: Received: 19 May 2020/ Revised: 23 June 2020/ Accepted: 27 July 2020/ Published: 31 August 2020

Publisher: Online Science Publishing 


\section{Highlights of this paper}

- The paper depicts the leadership styles of oil and gas industries.

- This study found that in the current scenario where the Western world is trying to establish their entity in the oil and gas business, if an organisation is not guided properly by a leader, chances of crumbling down before the intense pressure is quite common.

\section{INTRODUCTION}

The study aims at discussing consequences and influence of leadership techniques in the development of employee performance focussing on Oil and Gas industries in Oman. Due to globalisation it is perceived that in Oman oil and gas industry it is extremely important to adapt strategic technique of leadership. According to Macey and Schneider (2008) in the economy of the country this industry has always performed to be major contributor. This sector has happened to be the largest industry in Oman and it is expanding. However, currently this industry is infested by increasing domestic demand and in order to cater to these needs Oman has placed successful program for boosting output of oil and foreign partnerships and investments are also being attracted in this regard. Expansive and modern infrastructure of Oman is supported by utilities of electricity, medical services, public education and roads. On the other hand, low prices of oil are pushing firms towards developing efficiencies forcing many of the players in the market to reduce base cost along with the workforce. Oman has natural reserves for gas which can play leading role in fuelling industrial growth of the sultanate in recent years. However, in the last decade Oman Oil and gas industry has confronted crucial drawbacks due to radical economic slowdown. This industry however has not yet achieved total recovery from such setback and therefore stability cannot be achieved yet. In 2014it is estimated that total expenditure is estimated in oil and gas industry as 11.5 billion US\$. In Oman organisations are capable of producing almost nine lakh barrels each day. Through a report by Nahrgang, Morgeson, and Hofmann (2011) it is understood that oil and gas industry has targeted growth by $22 \%$ by the year 2021. Due to the recent transformation in gas and oil industry in this country, Oman has seen shortage in labour skills. These are infesting this industry with high rates of turnover. For the oil companies increasing motivation is becoming the most fundamental issue and therefore retention of these employees have become major issue. In this context it has become increasingly important for this industry to develop standard of leadership in order to facilitate motivation of employees better. Poor appraisal of performance contributes greatly towards employee demotivation followed by the perceptions of recognition lack, unfair salary, and poor speculation of the role along with deficiency in empowerment. Sometimes in oil industry it is seen that non-monetary factors also result in employee de-motivation. Now managers and leaders in this organisation are therefore working towards using effective tools of leadership for facilitating long term impact of motivation on employees.

The leader in this organisation needs to keep balance and symmetry between technologies and manpower and thus is trying to accomplish goal of the organisation. Therefore, the leaders remaining in this industry need to employ their experience and skills for assuring this particular sector expansion and thus assuring expansion of the economy of the country (Saks \& Gruman, 2014). Similarly, leaders are also required to take appropriate decisions for fighting with challenges and odds of the sector. Leaders also are required to maintain an atmosphere of friendliness within organisations for motivating employees. It is recognised that appointing good leaders are utterly necessary in oil and gas sector in order to cater to the necessities of this industry of increasing employee performance. This industry can enliven its last glory only with the recruitment of effective leaders. The study is aimed at finding leadership performance standards and understanding the relationship between leadership style and employee performance emphasising on Oil and Gas industry in Oman. The research objectives are as follows.

- To understand impact of the style of leadership on employee performance. 
- To evaluate relationship between employee performance and effective approach of leadership.

- To recommend ways for developing employee performance in the organisation with special emphasis on oil and gas industry in Oman.

Leadership is considered as the process through which any executive can influence, guide and direct work and behaviour of others towards the achievement of particular goals in the in certain situation. Leadership as opined by Braun, Peus, Weisweiler, and Frey (2013) is a manager's ability for inducing the subordinates for working with zeal and confidence. Leadership is also understood as the behavioural influence on others. It is also realised as the capability or capacity for influencing the group towards accomplishment or goal realisation. Leaders in the organisation are driven towards developing future visions as well as motivating the members of organisation towards accomplishment of visions. According to Atmojo (2015) leadership is known as the ability for persuading others for seeking objectives quite enthusiastically. This very human factor acts as binding agent for the group and motivates them towards better future.

Great leaders have certain qualities and characteristics among them which differentiate them from the others. Great leaders always find opportunities or balance between character and performance, business foresight. Some of the characteristics like courage integrity, humility, vision along with strategic planning capability as well as catalysing cooperation definitely are the attributes of a good leader. There is intricate difference between workers and bosses, employees and management. Leaders are responsible for understanding this difference and thereby accept them. The performance of leaders sets them apart from employees and this is not the way suggesting that they are better but in the manner of retaining an objective perspective. Leaders are also characterised by their ability to create tough decisions and they are aware of the fact that under certain circumstances leaders need to take crucial decision for the benefit of their team. They are aware of the fact that under certain situations it is important to take timely and difficult decisions catering to the best interest of the organisation (Braun et al., 2013). Leaders realise it well that decisions are required to be firm, authoritative and should not drive towards leasing everyone. Extraordinary excellent leaders know it well when to foster collaborative decision making rather than performing unilaterally.
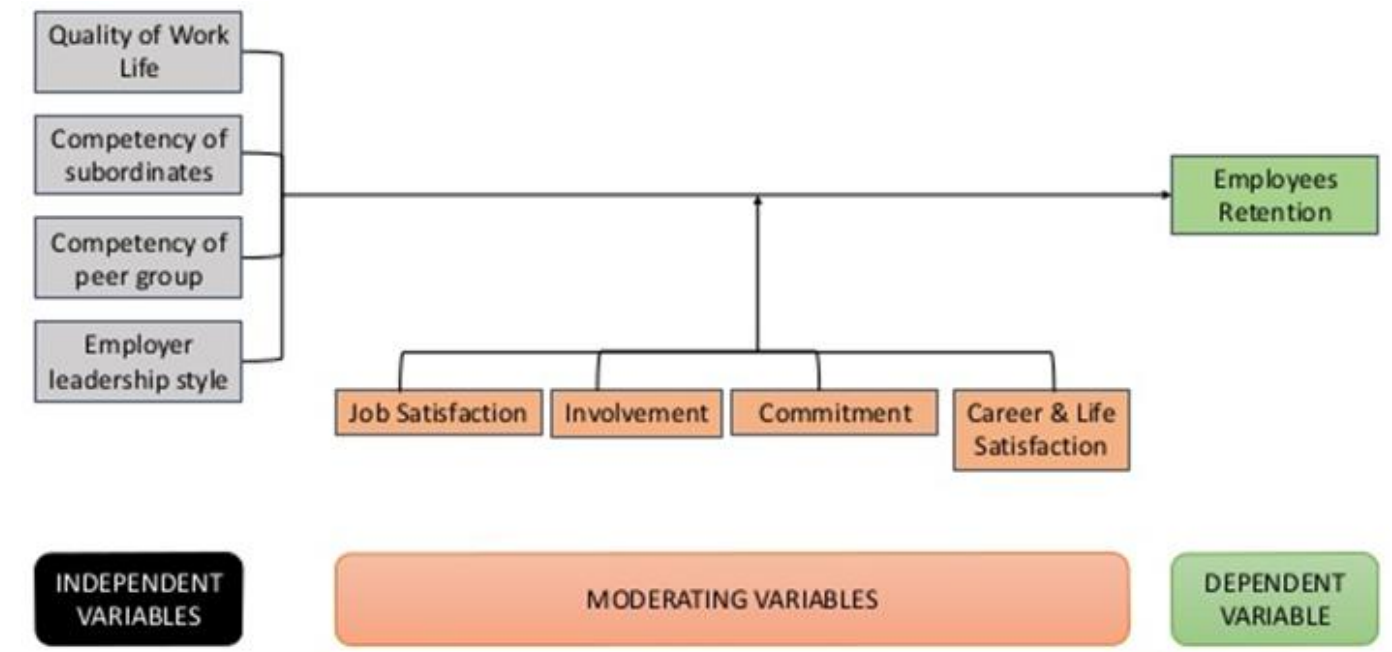

DEPENDENT VARIABLE

Figure-1. Conceptual framework

Extraordinary leaders possess the characteristic of empathy where they address issues in private and praise in public emerging from their genuine concern. Best of the leaders are responsible for guiding employees through the challenges and they always look for solutions fostering long-term success of organisation. Leaders often emphasises 
on moving forward along with constructive solutions rather than inclining towards being personal in terms of blaming individuals or encountering problems. Accountability is another attribute where they take the responsibility of the performance of everyone in team consisting of their own (Caillier, 2014). They are responsible for following outstanding issues, checking employees as well as speculating company procedures and policies. If things run well the leaders praise and also they recognise problems immediately and seek solution to get them back on the track. Best of the leaders not only possess confidence but also employees are drawn naturally by such confidence and seek advice along with feeling more confident.

Leaders have the most effective role to perform in organisational development. Modern organisations are characterised by globalisation which means change is an inevitable factor in organisational determent. Leaders are the individuals responsible for facilitating changes (Chen, Eberly, Chiang, Farh, \& Cheng, 2014). Leaders are the excellent communicators and develop certain vision aligning with the mission of the organisation. They ensure dividing the role of each of employees based on their skills and efficiency. They make employees to face challenging situation so that they can better understand and devise ways by themselves for coming out of those problems. While doing so leaders always consider staying by the side of their subordinates by solving their problems and helping them in every way for succeeding in their objective.

Trait leadership model is used for predicting effectiveness of the leaders. This leadership theory as stated by Cherian and Jacob (2013) highlights on the identification of different characteristics and traits of personality linked to the attributes of successful leaders across different situations. This leadership theory is aligned with GreatMan theory which believes that leadership characteristics are innate and it cannot be acquired as stated by Carlyle. His research is inspired by the previous studies on leadership and some of trait theory implications revolve around facts like certain behaviour patterns are developed by certain traits, across different situations such patterns are always consistent. The strength of trait theory are it is pleasing theory naturally, it is quite valid as lots of research works have validated the basis of this theory, serves as the yardstick against leadership characteristics of an individual and provides detailed understanding and knowledge regarding the element of leader in the process of leadership. On the contrary, it is limited by the subjective judgment of being successful and good leader, possible successful leadership traits are quite long too, disagreement also remains regarding certain traits and sometimes this model considers physical traits as the measurement scale for a successful leader (Gruman \& Saks, 2011).

Autocratic leadership style is also known by authoritarian leadership and is characterised through the attributes of control and less input from members in the group. Autocratic leaders consider making choices based on their judgment and decisions and rarely consider taking advice from members. Autocratic leadership as stated by Hoch (2013) constitutes of authoritarian as well as absolute control over the group. Effective and fast decisions stimulate from autocratic leaders when the person is the most knowledgeable one within the group (Hoon Song, Kolb, Hee Lee, \& Kyoung Kim, 2012). If leadership happens to be lacking in small groups then autocratic leadership technique also finds success. Sometimes people need to work under strict deadline and in this context taking everyone's decision may result in losing deadline and can have negative impact on tyre project. In such circumstances things do work better when one individual is burdened with the responsibility of handling the team, assign different members different tasks based on their capability and potential accompanied by attributing solid deadlines for finishing each of the project. Through setting distinct goals, establishing definite deadlines, assigning tasks the group tend to complete project on time where everyone is responsible for giving their equal contributions.

Military, construction as well as manufacturing industries are utterly facilitated by such autocratic leadership style. On the contrary, Liden, Wayne, Liao, and Meuser (2014) has stated that under certain circumstances autocratic leadership style often confronts failure as employees often perceive them as dictatorial, bossy and 
controlling causing resentment among the members of the group. As autocratic leaders prefer taking decisions without interacting with the members of the group people often feel that their ideas are undervalued. Contingency theory is categorised under certain form of behavioural theory which contends the fact there is not any perfect or best theory of leadership. Rather perfection of leadership stems from the situational demands and the ability of leaders to cater to this situation. Contingency theory can be assimilated with the situational theory tending to emphasise more on those behaviours that leaders need to embrace under certain situational factors (Sharif \& Scandura, 2014). Contingency theory therefore emphasises on both the personality of leader as well as situation where they operate. Fiedler along with his associates therefore has outlined two leadership styles including relationship-oriented and task-motivated characteristics. This contingency leadership theory is further categorised into other divisions.

Currently it has become increasingly important for creating the workforce with high level of performance and this cannot be possible without highly inspired organisational members. Transformational leadership is presently perceived in every organisation, in departments, teams, as well as divisions. These leaders have the attributes of being visionary, daring, inspiring, risk-takers and thoughtful individuals. These leaders possess charismatic trait yet it is also true that only charisma is quite insufficient for changing organisational operation and therefore transformational leaders are majorly known for their four primary characteristics (Sundi, 2013). Transformation leaders have the inspiration towards motivation as their efforts stimulate from establishment of consistent mission, vision along with set values to members. They formulate compelling vision and consider guiding their followers with integrating a definite sense of challenge and meaning. Commitment and teamwork is fostered by their enthusiastic and optimistic contribution. The needs of their followers are placed above them and also never hesitate for sacrificing personal gains and are responsible for creating high ethical standards. On the contrary, Tims, Bakker, and Xanthopoulou (2011) have stated that transformational leadership utilises impression management and thus lands often to amoral promotion of self by leaders. This transformational leadership theory is actually an amalgamation of different styles and theories of leadership and therefore it is difficult to teach. Sometimes, chances of losing preoccupy gain as the followers often get manipulated by the leaders.

Transactional leadership emphasises on basic processor management like organising, controlling along with short-term planning. Unlike transformational leaders, leaders driven by transactional theory consider directing and motivating their followers through catering to their personal self-interest. This leadership theory has faith in system of punishment and rewards for facilitating motivation (Troena \& Noermijati, 2013). Here primary objective of the leaders lie formal authority. Therefore primary goal of the follower is obeying instructions of leaders. This style is also known as telling style. Due to measurable nature of this leadership job satisfaction and performance of employees can be accomplished (Wallace, de Chernatony, \& Buil, 2013). Extra stimulus is also achieved by employees through the delivery of reward. For influencing employees transactional leaders delegate two of the factors. Rewards are responsible for instigating better performance and organisations also receive benefit. Interim review is carried out by such leaders in order to understand which employee is more deserving kin achieving the award. Visionary leaders have good skills of communication and therefore these leaders are ware of ways to verbalise goals and dreams and appropriately explain them to the team. However, for leader communication cannot be regarded as one sided and the excellence of visionary leader lies not only in dictating ideas rather than listening to others ideas as well. Visionaries assist the team in reaching their milestones along with personal goals of leaders (Wang, Tsai, \& Tsai, 2014). Visionary leaders are also defined by their charisma. Merriam-Webster has stated that charisma can be referred as personal magic in leadership bearing special loyalty. However, everybody is not born with their personal magic but also they can cultivate and learn that. Charisma is considered as natural attraction 
drawing people towards the enthusiasm of the leader as well as the leader. Laissez-Faire leadership style is regarded as non-authoritarian leadership and the characteristics of these leaders are engraved in having clear standards, communication and objectives which are important for succeed. In current scenario this form of leadership is considered to be the best. This leadership also known as delegate leadership allow members of the group to make decisions. In Merriam-Webster dictionary, Laissez-Faire leadership has been defined as the practice or philosophy characterised by deliberate abstention from interference or direction focusing on individual actions and freedom of choice (Xu \& Thomas, 2011). This leadership style is responsible for empowering individuals, teams or groups for making decisions though critics of this style considers that it is utterly risky to leave decision making responsibilities on staff members. These leaders are characterised by their attribute of attributing complete freedom in follower in terms of making decisions though leaders offer all necessary resources and tools.

Leaders have immense significance in employee performance and they mostly inspire employees with their outstanding and clear vision, resolving conflicts among individuals and integrating that vision with others. Leaders involve them in the development of definite set of values and mission for operating the company. Leaders influence in developing performance level of employees through increasing motivation level. They are utterly passionate towards their work which integrates positive energy in the group this positive energy help employees in pulling up the organisation with their efforts. Great leaders as opined by Yao, Chen, and Cai (2013) possess deep reserves in the context of spiritual, emotional and physical energy and supportive along with strong relationship between employees and leaders fuel this energy. Organisation run with the power of employees. Effective leaders understand this fact and put employees as their priority list. Leaders are often characterised through their communication.

\section{METHODS}

Due to globalised nature of the current market oil and gas industry is suffering more pressure for developing better organisational culture and employee performance. It has become in oil and gas industry to develop an effective organisational culture to develop or enhance the performance of employees. Organisational culture as stated by Zhang, Huai, and Xie (2015) can be reflected in terms of shared symbols, assumptions, values, norms and beliefs specifying ways through which employees understand problems and react to those appropriately. In this relation analysing relationship between firm performance and corporate culture become important and this can be visualised by three crucial dimensions including learning, trust and collaboration. Oil and gas companies have been effectively benefitted through the integration of trust and collaboration. This trust and collaboration are integral for oil and gas industry in the context of responding to the changes in environment, needs of employee growth and customers through the development of effective learning workplace within organisation.

Oil and gas industry has the intense necessity of addressing problematic situations and the capability of combining old with the new. In other words, oil and gas industry is driven by the urge of being more creative and innovative. In order to prepare the organisational culture and develop employee performance oil and gas industry leaders need to embrace certain behaviours. In this relation, leaders and managers need to communicate their clear expectations and goals to the employees. Most of the employees want to be the part of compelling future and in order to succeed in any project managers need to communicate goals to them clearly and discuss effective and meaningful targets for motivating such employees. Workforce requires to be informed regarding organisational change, work policies along with job expectations. According to Zhang et al. (2015) employees perform better if they feel that their opinion are valued in the organisation and therefore it is important to five them the chance to share their perception. Reluctance in sharing full information can also result in not understanding properly by the employees their job roles and lack of understanding objectives of business. Training of the employees are also 
important in order to make them better understand their job role and developing power of innovative thinking. In this context, leaders and managers must involve them in indulging employees in challenging jobs. At the same time it is also important to encourage employees to come to them with their problems. Managers and leaders need to solve problems of employees as well as encourage them to place their own opinions for solving the problems. However, under certain context it is important to adopt autocratic behaviour to develop employee performance, especially when there is strict deadline and less time is there for taking into account of the perspectives of employees. For oil and gas industry n amalgamation of autocratic and Laissez-Faire leadership techniques can work wondrous. The current research has used the non probability open ended sampling technique for the current study. A questionnaire of 18 multiple choice questions has been forwarded to 64 employees working with different oil and gas companies of Oman: 20 employees of Oman Oil Marketing Company, 23 employees of Oman Oil Company, 21 employees of Petroleum development of Oman). The study has not been limited with the Omanis respondents only, rather employees of different countries working with these organisations are also given chance to participate in the study. Total number of respondents used for this particular study is considered to be the sample size. In this particular research context, therefore, total sample size is 64 . In order to analyse and interpret the collected data and information, the researcher has used correlation data analysis technique, mean, chi-square technique and other significant and well known procedures. At the same time, proper statistics has been used for this study in order to analyse the study in a better way.

\section{RESULTS AND DISCUSSION}

In relation to the analysis of responses, it is identified that the commanding nature of leaders and the involvement of the employees in decision-making process are the independent variables. The affect of leadership style on the employee's' performance is the dependent variable. The mean values of the questions are 1.3438, 2.2187 and 3.0781. The mean value of the third question is not supportive of the views of the respondents. The standard deviation values are .56957, 1.41947 and 1.54616. The standard deviation values have huge differences from 1. Therefore, there are huge problems in future in relation to commanding nature of leaders, involvement of decisionmaking process of the employees and the affect of current leadership style. The correlation values are positive for the independent and dependent variables. Thus, the performance of the employees is strongly affected by the two identified independent variables. The management should involve the employees in decision-making process and must change the commanding nature to reduce the identified future problems in the industry. Thus, the performance of the employees will be positively affected.

\subsection{Descriptive Statistics and Correlation Analysis}

Here based on the analysis of questions, the independent variable is the preferable type of reward system and the dependent variable is the impact of monetary rewards on the performance level. The mean values of the questions are 2.5000 and 1.5625. Both the mean values are not supportive with the views of the respondents. The standard deviation values are 1.43649 and .50000 . The high differences of standard deviation values signify that there might be huge problems in future in the industry for developing the performance level with extrinsic rewards.

Table-1. Descriptive statistics.

\begin{tabular}{lcccccc}
\hline Variable & N & Minimum & Maximum & Mean & Std. Deviation & Variance \\
\hline Affect of leadership style & 64 & 1.00 & 3.00 & 1.3438 & .56957 & .324 \\
Commanding of leaders & 64 & 1.00 & 5.00 & 2.2187 & 1.41947 \\
Views of decision making & 64 & 1.00 & 5.00 & 3.0781 & 1.54616 \\
Valid N (list wise) & 64 & & & & 2.015 \\
\hline
\end{tabular}


Table-2. Correlations.

\begin{tabular}{|c|c|c|c|c|}
\hline Variable & Test & $\begin{array}{c}\text { Affect of } \\
\text { leadership style }\end{array}$ & $\begin{array}{l}\text { Commanding } \\
\text { of leaders }\end{array}$ & $\begin{array}{c}\text { Views of } \\
\text { decision making }\end{array}$ \\
\hline \multirow{5}{*}{$\begin{array}{l}\text { Affect of } \\
\text { leadership style }\end{array}$} & Pearson Correlation & 1 & .023 & .005 \\
\hline & Sig. (2-tailed) & & .855 & .968 \\
\hline & $\begin{array}{l}\text { Sum of Squares and Cross- } \\
\text { products }\end{array}$ & 20.438 & 1.188 & .281 \\
\hline & Covariance & .324 & .019 & .004 \\
\hline & $\mathrm{N}$ & 64 & 64 & 64 \\
\hline \multirow{5}{*}{$\begin{array}{l}\text { Commanding of } \\
\text { leaders }\end{array}$} & Pearson Correlation & .023 & 1 & .209 \\
\hline & Sig. (2-tailed) & .855 & & .097 \\
\hline & $\begin{array}{l}\text { Sum of Squares and Cross- } \\
\text { products }\end{array}$ & 1.188 & 126.938 & 28.906 \\
\hline & Covariance & .019 & 2.015 & .459 \\
\hline & $\mathrm{N}$ & 64 & 64 & 64 \\
\hline \multirow{5}{*}{$\begin{array}{l}\text { Views of } \\
\text { decision making }\end{array}$} & Pearson Correlation & .005 & .209 & 1 \\
\hline & Sig. (2-tailed) & .968 & .097 & \\
\hline & $\begin{array}{l}\text { Sum of Squares and Cross- } \\
\text { products }\end{array}$ & .281 & 28.906 & 150.609 \\
\hline & Covariance & .004 & .459 & 2.391 \\
\hline & $\mathrm{N}$ & 64 & 64 & 64 \\
\hline
\end{tabular}

The management should focus on both intrinsic and extrinsic rewards. The Pearson correlation values are .044 and 1 . The negative value of dependent variable states that the performance of the employees in this industry does not depend on the extrinsic rewards. It also depends on the intrinsic or non-monetary rewards. Therefore, the performance of the employees can be improved if the management provides both intrinsic and extrinsic rewards to the employees of the oil and gas industry of Oman.

Table-3. Descriptive statistics.

\begin{tabular}{lcccccc}
\hline Variable & N & Minimum & Maximum & Mean & Std. Deviation & Variance \\
\hline Impact of monetary rewards & 64 & 1.00 & 5.00 & 2.5000 & 1.43649 & 2.063 \\
Preferable reward system & 64 & 1.00 & 2.00 & 1.5625 & .50000 \\
Valid N (list wise) & 64 & & & & .250 \\
\hline
\end{tabular}

Table-4. Correlations.

\begin{tabular}{|c|c|c|c|}
\hline Variable & Test & $\begin{array}{c}\text { Impact of } \\
\text { monetary rewards }\end{array}$ & $\begin{array}{c}\text { Preferable reward } \\
\text { system }\end{array}$ \\
\hline \multirow[t]{5}{*}{ Impact of monetary rewards } & Pearson Correlation & 1 & -.044 \\
\hline & Sig. (2-tailed) & & .729 \\
\hline & $\begin{array}{l}\text { Sum of Squares and Cross- } \\
\text { products }\end{array}$ & 130.000 & -2.000 \\
\hline & Covariance & 2.063 & -.032 \\
\hline & $\mathrm{N}$ & 64 & 64 \\
\hline \multirow[t]{5}{*}{ Preferable reward system } & Pearson Correlation & -.044 & 1 \\
\hline & Sig. (2-tailed) & .729 & \\
\hline & $\begin{array}{l}\text { Sum of Squares and Cross- } \\
\text { products }\end{array}$ & -2.000 & 15.750 \\
\hline & Covariance & -.032 & .250 \\
\hline & $\mathrm{N}$ & 64 & 64 \\
\hline
\end{tabular}

Here the responses reveal, the independent variable is the approach of employees to leaders for getting solutions. The dependent variables are the support of leaders and the support of support of superiors to increase the performance level. The mean values of these questions are 3.1250, 3.3125 and 2.7656. The mean values are supportive with the views of the respondents. However, there are slight changes observed in the views. The standard deviation values are 1.46385, 1.48938 and 1.61090. The values have large differences from 1 . Thus, it can 
be stated that the support of the leaders and the superiors are not enough to improve the performance level and to solve problems. This may create problem for the industry in future. The Pearson correlation values are 1, .011 and .142. The support of the superiors to improve the performance level does not depend on the problem solution process of the leaders. However, the support is necessary to motivate the employees. Thus, the superiors of the Oil and Gas industry of Oman should support the employees for improving the performance level as well as to solve problems.

Table-5. Descriptive statistics.

\begin{tabular}{lcccccc}
\hline Variable & \multicolumn{3}{c}{ Table-5. Descriptive statistics. } & & \\
\hline Solution from leaders & N & Minimum & Maximum & Mean & Std. Deviation & Variance \\
Support of managers & 64 & 1.00 & 5.00 & 3.1250 & 1.46385 & 2.143 \\
Importance of superior support & 64 & 1.00 & 5.00 & 3.3125 & 1.48938 & 2.218 \\
Valid N (list wise) & 64 & 1.00 & 5.00 & 2.7656 & 1.61090 \\
\hline
\end{tabular}

Table-6. Correlations

\begin{tabular}{|c|c|c|c|c|}
\hline Variable & Test & $\begin{array}{c}\text { Solution } \\
\text { from leaders }\end{array}$ & $\begin{array}{l}\text { Support of } \\
\text { managers }\end{array}$ & $\begin{array}{c}\text { Importance of } \\
\text { superior support }\end{array}$ \\
\hline \multirow{5}{*}{$\begin{array}{l}\text { Solution } \\
\text { leaders }\end{array}$} & Pearson Correlation & 1 & .011 & -.142 \\
\hline & Sig. (2-tailed) & & .932 & .262 \\
\hline & Sum of Squares and Cross-products & 135.000 & 1.500 & -21.125 \\
\hline & Covariance & 2.143 & .024 & -.335 \\
\hline & $\mathrm{N}$ & 64 & 64 & 64 \\
\hline \multirow{5}{*}{$\begin{array}{l}\text { Support } \\
\text { managers }\end{array}$} & Pearson Correlation & .011 & 1 & .044 \\
\hline & Sig. (2-tailed) & .932 & & .728 \\
\hline & Sum of Squares and Cross-products & 1.500 & 139.750 & 6.688 \\
\hline & Covariance & .024 & 2.218 & .106 \\
\hline & $\mathrm{N}$ & 64 & 64 & 64 \\
\hline \multirow{5}{*}{$\begin{array}{l}\text { Importance of } \\
\text { superior support }\end{array}$} & Pearson Correlation & -.142 & .044 & 1 \\
\hline & Sig. (2-tailed) & .262 & .728 & \\
\hline & Sum of Squares and Cross-products & -21.125 & 6.688 & 163.484 \\
\hline & Covariance & -.335 & .106 & 2.595 \\
\hline & $\mathrm{N}$ & 64 & 64 & 64 \\
\hline
\end{tabular}

According to the analysis of responses, the independent variable is communication of leaders in every matter. The dependent variable is the transparency maintaining by the leaders of the Oil and Gas industry of Oman. The mean values are 3.2344 and 3.1719. The mean values are supportive with the opinions of the respondents. Therefore, the leaders of the industry do not maintain proper communication and transparency with the subordinates. The standard deviation values are 1.48796 and 1.54873. The high standard deviation values show high amount of risks for the industry. In case, if the organizations of the industry do not focus to minimize the problems then it will create impact on the performance of the employees. The Pearson correlation values are 1 and.003. The positive values exhibit strong relationship between the variables. Thus, the transparency of the leaders can be increased if the leaders communicate with the employees in every matter. This is necessary to develop the performance of the employees as well as the industry. 
Table-7. Descriptive statistics.

\begin{tabular}{lcccccc}
\hline Variable & N & Minimum & Maximum & Mean & Std. Deviation & Variance \\
\hline Transparency maintenance & 64 & 1.00 & 5.00 & 3.2344 & 1.48796 & 2.214 \\
Communication of leaders & 64 & 1.00 & 5.00 & 3.1719 & 1.54873 & 2.399 \\
Valid N (list wise) & 64 & & & & & \\
\hline
\end{tabular}

\begin{tabular}{llcc}
\hline Variable & Test & $\begin{array}{c}\text { Table-8. Correlations. } \\
\text { Transparency } \\
\text { maintenance }\end{array}$ & $\begin{array}{c}\text { Communication } \\
\text { of leaders }\end{array}$ \\
\hline Transparency maintenance & Pearson Correlation & 1 & .003 \\
& Sig. (2-tailed) & & .982 \\
& Sum of Squares and Cross-products & 139.484 & .422 \\
& Covariance & 2.214 & .007 \\
& $\mathrm{~N}$ & 64 & 64 \\
Communication of leaders & Pearson Correlation & .003 & 1 \\
& Sig. (2-tailed) & .982 & .422 \\
& Sum of Squares and Cross-products & .007 & 151.109 \\
& Covariance & 64 & 2.399 \\
\hline
\end{tabular}

In the context of analysis of responses, the training provided by the leaders and the dependent variable is the increase of performance by effective management of the team. The mean values of these questions are 3.4531 and 2.1719. The mean values have significant relationship with the views of the respondents. Only, there is a controversy among the employees that whether the leaders provide training to them or not. The standard deviation values are 1.53198 and 1.38650 . The high values justify that the industry may face problem in future if the leaders do not provide training to all the employees. Some employees obtain training from the leaders. The Pearson correlation values are 1 and .082. The positive values deliver strong relationship between the variables and the leaders should provide training to increase the performance through effective management. The training is significantly important to increase the level of performance of the employees.

Table-9. Descriptive statistics.

\begin{tabular}{|c|c|c|c|c|c|c|}
\hline Variable & $\mathbf{N}$ & Minimum & Maximum & Mean & Std. Deviation & Variance \\
\hline Training by leaders & 64 & 1.00 & 5.00 & 3.4531 & 1.53198 & 2.347 \\
\hline Effective team management & 64 & 1.00 & 5.00 & 2.1719 & 1.38650 & 1.922 \\
\hline Valid N (list wise) & \multicolumn{4}{|l|}{64} & & \\
\hline \multicolumn{7}{|c|}{ Table-10. Correlations. } \\
\hline Variable & \multicolumn{3}{|c|}{ Test } & & $\begin{array}{l}\text { Training by } \\
\text { leaders }\end{array}$ & $\begin{array}{l}\text { ffective team } \\
\text { management }\end{array}$ \\
\hline \multirow[t]{5}{*}{ Training by leaders } & \multicolumn{3}{|c|}{ Pearson Correlation } & & 1 & .082 \\
\hline & \multicolumn{3}{|c|}{ Sig. (2-tailed) } & & & .518 \\
\hline & \multicolumn{3}{|c|}{ Sum of Squares and Cross-products } & & 147.859 & 11.016 \\
\hline & \multicolumn{3}{|c|}{ Covariance } & & 2.347 & .175 \\
\hline & \multicolumn{3}{|c|}{$\mathrm{N}$} & & 64 & 64 \\
\hline \multirow[t]{5}{*}{ Effective team management } & \multicolumn{3}{|c|}{ Pearson Correlation } & & .082 & 1 \\
\hline & \multicolumn{3}{|c|}{ Sig. (2-tailed) } & & .518 & \\
\hline & \multicolumn{3}{|c|}{ Sum of Squares and Cross-products } & & 11.016 & 121.109 \\
\hline & \multicolumn{3}{|c|}{ Covariance } & & .175 & 1.922 \\
\hline & \multicolumn{3}{|l|}{$\mathrm{N}$} & & 64 & 64 \\
\hline
\end{tabular}

Here, the independent variable is the setting of clear expectations for every employee by the leaders and the dependent variable is the freedom of performing own job role. The mean values are 2.6406 and 1.7500. Both the mean values are supportive with the views of the respondents. The standard deviation values are 1.44054 and .64242. The standard deviation values are very high and therefore, some risks are present in the variables. The leaders do not set cleat expectations for the employees and the employees work under pressure to satisfy the higher 
authority. In case, if the leaders fail to set clear expectations then the employees do not obtain freedom to perform their job roles. The Pearson correlation values are 1 and -.184. Thus, the variables do not have any relationship between them. The leaders should provide freedom to the employees by setting clear expectations for them.

Table-11. Descriptive statistics.

\begin{tabular}{|c|c|c|c|c|c|c|}
\hline Variable & $\mathbf{N}$ & Minimum & Maximum & Mean & Std. Deviatiol & Variance \\
\hline Expectation of freedom & 64 & 1.00 & 5.00 & 2.6406 & 1.44054 & 2.075 \\
\hline Set clear expectations & 64 & 1.00 & 3.00 & 1.7500 & .64242 & .413 \\
\hline Valid N (list wise) & 64 & & & & & \\
\hline \multicolumn{7}{|c|}{ Table-12. Correlations. } \\
\hline Variable & \multicolumn{2}{|c|}{ Test } & & & $\begin{array}{l}\text { Expectation } \\
\text { of freedom }\end{array}$ & $\begin{array}{c}\text { Set clear } \\
\text { expectations }\end{array}$ \\
\hline \multirow[t]{5}{*}{ Expectation of freedom } & \multicolumn{4}{|c|}{ Pearson Correlation } & 1 & -.184 \\
\hline & \multicolumn{4}{|c|}{ Sig. (2-tailed) } & & .145 \\
\hline & \multicolumn{4}{|c|}{ Sum of Squares and Cross-products } & 130.734 & -10.750 \\
\hline & \multicolumn{4}{|c|}{ Covariance } & 2.075 & -.171 \\
\hline & \multicolumn{4}{|c|}{$\mathrm{N}$} & 64 & 64 \\
\hline \multirow[t]{5}{*}{ Set clear expectations } & \multicolumn{4}{|c|}{ Pearson Correlation } & -.184 & 1 \\
\hline & \multicolumn{4}{|c|}{ Sig. (2-tailed) } & .145 & \\
\hline & \multicolumn{4}{|c|}{ Sum of Squares and Cross-products } & -10.750 & 26.000 \\
\hline & \multicolumn{4}{|c|}{ Covariance } & -.171 & .413 \\
\hline & \multicolumn{4}{|c|}{$\mathrm{N}$} & 64 & 64 \\
\hline
\end{tabular}

The feedback provided by the managers is the independent variable and the appreciation of the works is the dependent variable. The mean values or the questions are 3.3750 and 3.7031 . Both the values have relation with the opinions of the respondents. The standard deviation values are 1.32737 and 1.21733. The values exhibit moderate amount of risks in these variables. The leaders do not provide proper feedback to the employees to motivate them. In this way, the employees are becoming demotivated. The leaders should provide more feedback with appreciation to develop the performance of the employees in Oil and Gas industry of Oman. The Pearson correlation values of the variables are 1 and -.058. The negative value signifies that the appreciation does not depend on the feedback of the performance provided by the leaders. However, the feedback can help the leaders to appreciate the works of the employees.

Table-13. Descriptive statistics.

\begin{tabular}{lcccccc}
\hline Variable & N & Minimum & Maximum & Mean & Std. Deviation & Variance \\
\hline Feedback from managers & 64 & 1.00 & 5.00 & 3.3750 & 1.32737 & 1.762 \\
Managers appreciation & 64 & 1.00 & 5.00 & 3.7031 & 1.21733 \\
Valid N (list wise) & 64 & & & & & 1.482 \\
\hline
\end{tabular}

Table-14. Correlation table.

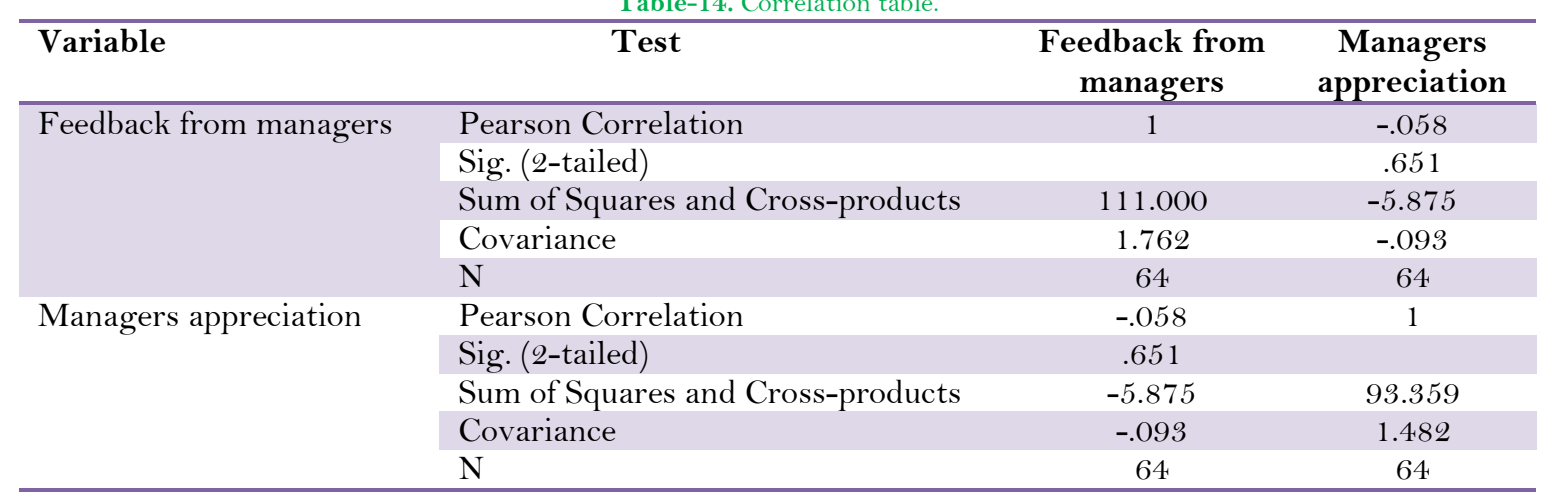


The analysis provides that the independent variables are the responsibilities of the managers to scrutinize the performance of the employees and putting the employees in the challenging situations. The dependent variable is the caring of managers to take the responsibility of the team. The mean values are 3.2188, 3.0625 and 3.5469. The mean values are supportive of the marked options of the respondents. Therefore, the opinions of the respondents are true. The standard deviation values are 1.59830, 1.53142 and 1.42461. The high values present high risks for the company as the managers do not perform their responsibilities properly. The Pearson correlation values 1, -.038 and .086. The negative value exhibits poor relationship among the variables. Thus, the dependent variable is not dependent on the independent variables. The leaders of the Oil and Gas industry of Oman should conduct their responsibilities properly.

Table-15. Descriptive table.

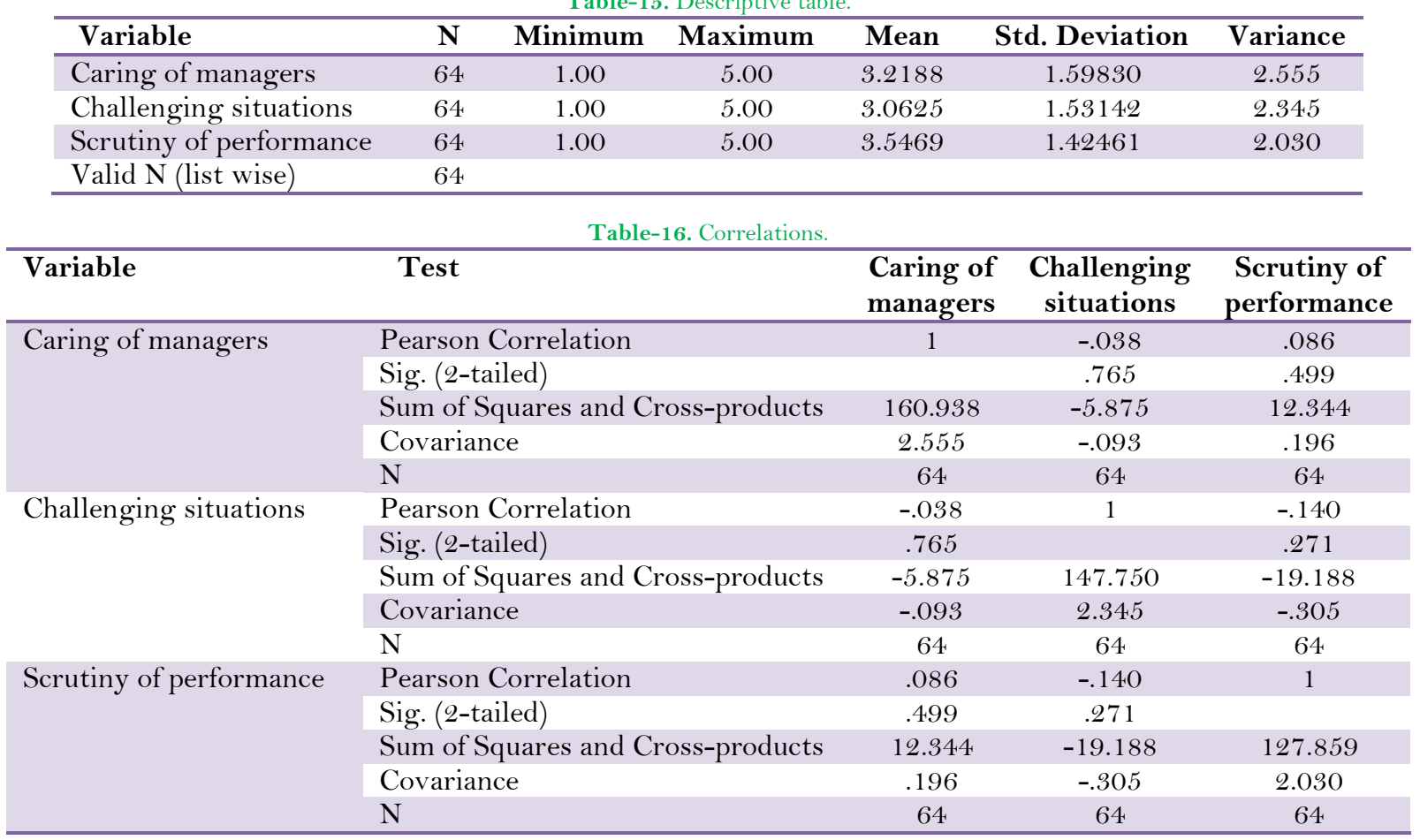

From the above analysis, it is identified that the performance of the leaders and managers in Oil and Gas industry of Oman is poor. They also do not perform their responsibilities in relation to scrutinize the employee's performance, set expectations for the employees and putting them in challenging situation. The reward system of the industry is not preferable to motivate the employees. The communication technique adopted by the leaders is not supportive to solve problems. Thus, the performance of the employees is becoming poorer in comparison to other industries.

\section{CONCLUSION}

The findings of the study highlights that democratic and transformational leadership style are mostly followed in most of the oil and gas organisations in Oman, followed by the laissez faire. For the overall development of the employees and motivating them to perform well, engagement of the leaders with their subordinates is literally essential. It is quite evident from the responses of the employees that they get the leaders of their organisation by their side when they are in trouble. Besides, the leadership approach in this regard is quite effective in the development of organisational ethics. Transactional leadership style has been effectively found to be correlated with 
the performance of the employees and thereby helps in overall performance development of the organisation. But in no way there has been any plot open for authoritative leadership style. In most of the cases authoritative leaders do not look for the development of the other people rather concentrates on personal development. The study has also researched it out that employee performance is directly related to that of the leadership strategy. This is because a leader motivates the employees circumnavigate through the serious challenges. The study witnesses that an employee can present its best skill for the development of the organisation if he or she is guided in a proper way. At the same time, it helps the employee to attain the mental satisfaction which in the long run again ascertains the prosthetic development as a whole. The study evidently projects that the personality of a leader is also quite important in this regard. A leader, in one hand, should be bold and foreseer while on the other hand must be a good decision making and a problem solver. The comprehensive approach of the leader does not only guide the leader to attain better cognizance within the organisation, it is also their dedication in their work that enable them to influence other subordinate employees of the organisation. The leadership approach, as the study has sophistically found out, should be direct and straight forward. There is no scope for a leader to retreat from its point as it may lead to demotivate the employees.

The leadership approach performed by the leaders in the oil and gas industries of Oman is seen to be quite unique and identical. Since a leader stands amongst the employees it also helps them to face the challenges in the right way. A determined leader always acts identically. The leaders of oil and gas organisations also act closely with the management. The study has observed that leadership exists in all layers of the organisation, however, the necessity of the leaders is felt only when there is a necessity to motivate the others and take the appropriate decisions. Overall accomplishment of the system or the organisation is the primary necessity engaged with leadership. The study has effectively observed that after recognizing leadership a system or an approach, it is particularly essential to understand the relationship between the leaders and their constituents.

It is quite evidently mentioned in the context of the study that oil and gas organisations Oman are needed to comply with democratic leadership strategy as it has a long term impact on the development of the organisation as a whole. The study has also denoted that the leaders in this context must not only understand the situation but should be capable of taking the rightful decisions. The study has also highlighted that most of the employees working in different oil and gas organisation in Oman do not feel motivated with their leader's attitude. So the leader must be capable of handling the workforce along with the other significant resources.

Needless to say, the study has successfully presented the impact of the leadership style and approaches on the employees. So, the objective set beforehand has been successful. In most of the cases the respondents seems to have noted that the organisation along with the leaders give them priority in taking the decisions. The leaders are seemed to stand by them during all the circumstances. At the same time, it helps in building the operational base. Not the leaders only, managers, team leaders and other senior employees of the organisation should also act coordinating with the employees so that they can devote their best skills for the development of the organisation.

It is evident from the responses given by the respondents that without the guidance of the superiors they would not have performed so much well for the organisational development. Transparency in the operations, providing rewards, cultural integrity and other significant factors are proven to be quite motivating for the employees. Importance of the management team for the development of the employees' sake is another significant approach seems to be managed in this regard. Freedom of the employees eventually help the organisation to develop in its course and also ensures that the employees are provided the free thinking facilities. It is evident from the respondents' response that the organisational integrity can be attained with a responsible team with skilled and responsible employees deploying their best for the perpetual development of the organisation. The leaders and 
senior employees of the organisation can lead the workforce to attain better opportunities which in turn would help the organisation to grow and attain the competitive advantages of the market place.

In order to enrich the employee performance in oil and gas industry in Oman, the primary issue that the organisations should focus on building the gravity of the employees. Employing the experienced staffs would be particularly important in this regard. This approach in one hand would help the organisation grow in the market which on the other hand would also enable the organisation attain the competitive advantages. The study has definitively suggested that the role of a leader should be should not be limited within leading the organisation. Rather they should also particularly focus on the ethical development of the employees. The study has also suggested that application of democratic and laissez faire leadership strategy can prove to be quite important and effective in the case of oil and gas industry of Oman. It would eventually help the employees to take decisions and again it would have a sophisticated impact on the growth of the organisation as a whole. The person who leads the organisation must adhere to all the necessary policies and must be confident enough to take necessary risks by breaking the conventional structure. Commitment of the leader towards the employees is another significant quality that enables the leader evade the threats of the unnecessary conflicts that come o the way. The leader should give priority to the opinion and though of the employees so that they can understand their position in the organisation and act with utmost loyalty. Compassionate about the job and responsibilities make a leader challenge all the possible threat that come on the way.

The results derived from this study highlights what does the employees desire from their supervisors and seniors and what kind of leadership approach they actually seek for. These information can essentially be used to develop the particular leadership strategies and the organisational behaviours attained in this course for the development of the leadership approach of the supervisor. The study has observed that transformational and democratic leadership approach normally leads to attain higher employee performance. It is always recommended that a leader or supervisor should always be innovative in his approaches and must be able to encourage the followers to enable them seek for more opportunities and possibilities. Naturally, the perimeter of a leader is needed to be expanded. It is although seem to be quite easy for an experienced leader however is quite difficult to understand and implement for a new leader. The prime value of the followers should be understood by a leader and the business strategies, plans, practices should be developed in that order so that they must comply with the unit or departmental business strategies. Leadership approach is literally a sophisticated matter that an organisation if not managed properly can turn out to be a destructive one. As oil and gas industry is needed to control a number of organisational operations at the same time, the role of the leadership literally high in nature. However, a little number of study has been conducted still these days. The current researcher seems to have hit the hive and tried to assess how leadership practices are leaving their impact on the perpetual development of the organisations. In order to fight against the current political and economic turmoil inflicted on by the Western world in the oil and gas market, a profound leadership of a person can help in circumnavigating through the challenges. Therefore, more study regarding this particular sector seems to have become an important matter these days.

\section{REFERENCES}

Atmojo, M. (2015). The influence of transformational leadership on job satisfaction, organizational commitment, and employee performance. International Research journal of Business Studies, 5(2), 113-128.

Braun, S., Peus, C., Weisweiler, S., \& Frey, D. (2013). Transformational leadership, job satisfaction, and team performance: A multilevel mediation model of trust. The Leadership Quarterly, 24(1), $270-283 . \quad$ Available at: https://doi.org/10.1016/j.leaqua.2012.11.006. 
Caillier, J. G. (2014). Toward a better understanding of the relationship between transformational leadership, public service motivation, mission valence, and employee performance: A preliminary study. Public Personnel Management, 43(2), 218239. Available at: https://doi.org/10.1177/0091026014528478.

Chen, X.-P., Eberly, M. B., Chiang, T.-J., Farh, J.-L., \& Cheng, B.-S. (2014). Affective trust in Chinese leaders: Linking paternalistic leadership to employee performance. Journal of Management, 4O(3), 796-819. Available at: https://doi.org/10.1177/0149206311410604.

Cherian, J., \& Jacob, J. (2013). Impact of self efficacy on motivation and performance of employees. International Journal of Business and Management, 8(14), 80-88.

Gruman, J. A., \& Saks, A. M. (2011). Performance management and employee engagement. Human Resource Management Revierw, 21(2), 123-136.

Hoch, J. E. (2013). Shared leadership and innovation: The role of vertical leadership and employee integrity. Journal of Business and Psychology, 28(2), 159-174.

Hoon Song, J., Kolb, J. A., Hee Lee, U., \& Kyoung Kim, H. (2012). Role of transformational leadership in effective organizational knowledge creation practices: Mediating effects of employees' work engagement. Human Resource Development Quarterly, 23(1), 65-101. Available at: https://doi.org/10.1002/hrdq.21120.

Liden, R. C., Wayne, S. J., Liao, C., \& Meuser, J. D. (2014). Servant leadership and serving culture: Influence on individual and unit performance. Academy of Management Journal, 57(5), 1434-1452. Available at: https://doi.org/10.5465/amj.2013.0034.

Macey, W. H., \& Schneider, B. (2008). The meaning of employee engagement. Industrial and organizational Psychology, 1(1), 3-30.

Nahrgang, J. D., Morgeson, F. P., \& Hofmann, D. A. (2011). Safety at work: a meta-analytic investigation of the link between job demands, job resources, burnout, engagement, and safety outcomes. Journal of Applied Psychology, 96(1), 71.

Saks, A. M., \& Gruman, J. A. (2014). What do we really know about employee engagement? Human Resource Development Quarterly, 25(2), 155-182. Available at: https://doi.org/10.1002/hrdq.21187.

Sharif, M. M., \& Scandura, T. A. (2014). Do perceptions of ethical conduct matter during organizational change? Ethical leadership and employee involvement. Journal of Business Ethics, 124(2), 185-196. Available at: https://doi.org/10.1007/s10551-013-1869-x.

Sundi, K. (2013). Effect of transformational leadership and transactional leadership on employee performance of Konawe Education department at Southeast Sulawesi province. International Journal of Business and Management Invention, 2(12), $50-58$.

Tims, M., Bakker, A. B., \& Xanthopoulou, D. (2011). Do transformational leaders enhance their followers' daily work engagement? The Leadership Quarterly, 22(1), 121-131. Available at: https://doi.org/10.1016/j.leaqua.2010.12.011.

Troena, E. A., \& Noermijati, N. (2013). Organizational citizenship behavior role in mediating the effect of transformational leadership, job satisfaction on employee performance: Studies in PT bank Syariah Mandiri Malang east Java. International Journal of Business and Management, 8(17), 1-12.

Wallace, E., De Chernatony, L., \& Buil, I. (2013). Building bank brands: How leadership behavior influences employee commitment. Journal of Business Research, 66(2), 165-171. Available at: https://doi.org/10.1016/j.jbusres.2012.07.009.

Wang, C.-J., Tsai, H.-T., \& Tsai, M.-T. (2014). Linking transformational leadership and employee creativity in the hospitality industry: The influences of creative role identity, creative self-efficacy, and job complexity. Tourism Management, 40, 79-89. Available at: https://doi.org/10.1016/j.tourman.2013.05.008.

Xu, J., \& Thomas, H. C. (2011). How can leaders achieve high employee engagement? Leadership and Organization Development Journal, 32(4), 399-416. 
Yao, Q., Chen, R., \& Cai, G. (2013). How internal marketing can cultivate psychological empowerment and enhance employee performance. Social Behavior and Personality: An international journal, 41(4), 529-537. Available at: https://doi.org/10.2224/sbp.2013.41.4.529.

Zhang, Y., Huai, M.-Y., \& Xie, Y.-H. (2015). Paternalistic leadership and employee voice in China: A dual process model. The Leadership Quarterly, 26(1), 25-36. Available at: https://doi.org/10.1016/j.leaqua.2014.01.002.

Online Science Publishing is not responsible or answerable for any loss, damage or liability, etc. caused in relation to/arising out of the use of the content. Any queries should be directed to the corresponding author of the article. 